\title{
Terapia génica como herramienta molecular para regenerar células ciliadas
}

\section{Genetic therapy as a molecular tool for hair cell regeneration}

\author{
Juan Cristóbal Maass 01,2, Loreto Carrasco M², Luis Dentone S ${ }^{1}$, Manuel Kukuluan P².
}

\begin{abstract}
RESUMEN
La hipoacusia es un gran problema de salud pública. Un daño frecuente encontrado es la pérdida irreversible de las células ciliadas de la cóclea, con preservación de células de sostén, fenómeno común en mamíferos. Las terapias existentes no están orientadas a solucionar el problema de fondo. Trabajos muestran que se puede obtener regeneración in vivo de células ciliadas y mejoría de los umbrales auditivos, mediante la sobrexpresión de Atoh1 en células de sostén del órgano de Corti (gen fundamental en desarrollo y diferenciación de células ciliadas). Existe evidencia experimental, de que la disminución de la expresión de genes con efecto opuesto puede estimular la proliferación y luego la transdiferenciación de células de sostén a células ciliadas. La investigación en este campo ayudará a entender el desarrollo y funcionamiento del oído interno en mamíferos y a que en el futuro se usen terapias de este tipo en pacientes sordos.
\end{abstract}

Palabras claves: Células ciliadas, regeneración, Atoh1, hipoacusia sensorioneural.

\begin{abstract}
Hearing loss is a major public health problem. A frequent type of damage, common in mammals, is the irreversible loss of cochlear hair cells, with preservation of the supporting cells. Current therapies are not oriented to solve the fundamental problem. The literature shows that in vivo regeneration of hair cells with auditory thresholds improvement is possible, using overexpression of Atoh1 (a key gene in the development and differentiation of hair cells) in the organ of Corti supporting cells. Experimental evidence shows that a decrease in the expression of genes that have the opposite effect may stimulate proliferation and posterior differentiation of supporting cells into hair cells. Research on this field will contribute to our understanding of the development and functioning of the mammal inner ear, and to the future use of this type of therapeutic intervention in deaf patients.
\end{abstract}

Key words: Hair cells, regeneration, Atoh1, sensorineural hearing loss.

La hipoacusia es un gran problema de salud pública, que afecta aproximadamente a 3 de 1.000 recién nacidos, lo que incrementa con el envejecimiento de la población afectando hasta el $50 \%$ de las personas de 75 años de edad ${ }^{1,2}$. Existen múltiples causas, que se podrían clasificar en las que afectan la llegada del estímulo mecánico al oído interno (de conducción) y las que se producen por daño directo de esta estructura (sensorioneurales). En estas últimas, el daño histopatológico más frecuente, involucra la pérdida

Médico Servicio de Otorrinolaringología, Hospital Clínico Universidad de Chile.

2 Médico Laboratorio de Neurobiología Celular y Molecular, Departamento de Fisiología y Biofísica, Facultad de Medicina, Universidad de Chile. 
irreversible de las células ciliadas de la cóclea con conservación del epitelio de sostén ${ }^{3,4}$. Existen en la cóclea dos tipos de células ciliadas: las internas, que poseen la capacidad de transformar ondas mecánicas en un estímulo eléctrico, y las externas, que participan en amplificar y sintonizar los estímulos ${ }^{5,6}$. Las terapias existentes hasta el momento están orientadas a modificar las características del estímulo y no a solucionar el problema de fondo (pérdida irreversible de las células ciliadas). Los audífonos amplifican el estímulo sonoro y el implante coclear realiza una estimulación directa y tonotópica sobre el nervio auditivo. Son tratamientos costosos y de difícil implementación lo que incrementa el impacto socioeconómico que tiene la discapacidad auditiva en la sociedad.

Hace más de cuarenta años se han buscado las claves que expliquen que este daño sea irreversible. Ruben en 1967, describe la ausencia de proliferación celular en cóclea de ratones a partir del día trece del desarrollo embrionario cuando se produciría la última mitosis 0 «mitosis terminal» ${ }^{7}$. Luego de esta división ocurre la diferenciación de las células del órgano de Corti ${ }^{8}$. Esta estructura en mamíferos es altamente estructurada y especializada. Dentro de ella no se ha identificado células progenitoras, y tanto las células ciliadas como las de sostén corresponden a un estado terminal de diferenciación ${ }^{8-10}$. Las investigaciones realizadas en este campo aún no han sido capaces de demostrar recambio ni regeneración espontánea luego de daño de células ciliadas de la cóclea de mamíferos ${ }^{7,10}$. Sin embargo, estos fenómenos se producen normalmente en células ciliadas de la línea lateral de peces ${ }^{11}$, de cócleas y vestíbulos de aves $^{12}$ y de utrículos de roedores ${ }^{13-15}$. En un estudio en cobayos luego de daño con aminoglicósidos se encontró dos a tres mitosis en las células de sostén por cóclea ${ }^{16}$. Todo esto es compatible con la idea de que durante la evolución se habría perdido la capacidad de proliferación y regeneración espontánea del epitelio sensorial de la cóclea. No se sabe la causa de esta pérdida eventual, qué factores la explicarían ni si tendría alguna función. Pero es posible que exista un potencial y que, luego de cambiar ciertas condiciones en las células, se produzca proliferación y regeneración coclear.

El desarrollo embrionario del oído interno es comandado por genes que intervienen en distintas etapas de éste y que a partir del neuroectodermo establecen patrones de desarrollo, especificando la formación de ciertos dominios, proliferación de ciertos tipos celulares y diferenciación de otros, determinando una arquitectura característica y críticamente conservada, ya sea por gradientes de expresión o por señales intercelulares que estimulan cascadas de señales. Es así como progresivamente se forman la placoda ótica, la vesícula ótica, la cóclea, el dominio prosensorial, las células ciliadas internas, externas y las células de sostén, con polaridad, número y posición adecuada ${ }^{9,10}$. Estos genes son comunes a la formación del sistema nervioso en general, así como también están presentes en la formación de otras estructuras $^{17-20}$. Muchos de ellos están alterados en pacientes con hipoacusia de causa genética (Ej: TBX1 y el $\mathrm{Sd}$. DiGeorge) y se han encontrado alteraciones severas en el desarrollo del oído interno en ratones knock-out (KO) para estos genes (KO: es aquel al que por medio de técnicas genéticas y de biología molecular se le ha «eliminado" al menos un gen). Algunos de ellos también se expresan en el oído interno adulto, su función no se conoce del todo y se utilizan a menudo como marcadores de ciertas células del órgano de Corti, ya que se expresan en forma diferencial en éstas. Estos genes codifican variados productos, pero los más estudiados son proteínas de membrana 0 secretadas (Ej.: Notch/ Delta-Jag1y2 y Fgfr3/Fgf8), factores de transcripción (proteína que es capaz de unirse a secuencias específicas de ADN con el objetivo de regular la transcripción. Ej.: Atoh1, Hes1, Hes5 y Tbx1) (Figuras 1 y 2 ), y reguladores del ciclo celular ( $\mathrm{pRb}$ y p27Kip1) ${ }^{8}$. La manipulación de la expresión de algunos de estos genes en el órgano de Corti ha producido proliferación celular y nuevas células ciliadas ${ }^{21-24}$, demostrando que existe un potencial regenerativo. Por ejemplo, al eliminar la expresión de $\mathrm{pRb}$ (retinoblastoma) mediante un $\mathrm{KO}$ condicional, las células ciliadas diferenciadas pueden volver al ciclo celular, dividirse y formar nuevas células ciliadas diferenciadas capaces establecer conexiones con el nervio auditivo ${ }^{21}$.

A pesar de que se desconocen los mecanismos involucrados y no se sabe a partir de qué tipo celular se pueden producir las nuevas células ciliadas (células de sostén, células ciliadas o progenitores), es importante buscar formas de rege- 


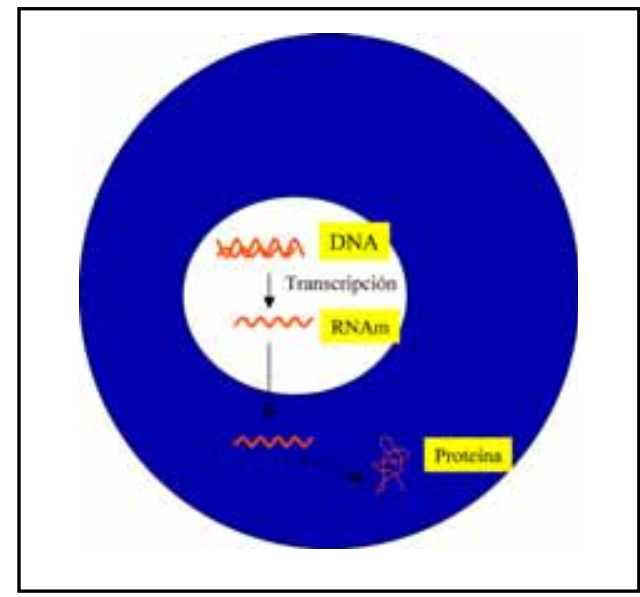

Figura 1. Síntesis proteica a partir de ADN: A través del proceso de transcripción se sintetiza ARN mensajero (ARNm) a partir de ADN.

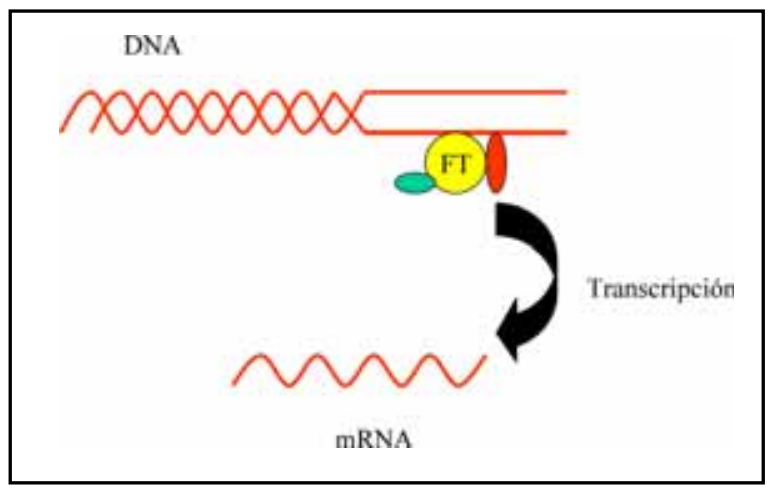

Figura 2. Factor de transcripción (FT): Proteína necesaria para iniciar la transcripción en organismos eucariontes. nerar células ciliadas in vivo para diseñar nuevas terapias para pacientes sordos.

El gen «atonal» de Drosophila melanogaster, codifica un factor de transcripción basic Helix-LoopHelix (bHLH) que es fundamental en el desarrollo de los órganos cordotonales de la mosca (sentido de audición, y detección de vibración, presión y altitud) ${ }^{25-}$ 27. Atoh1 (gen homólogo de atonal en mamíferos), es un gen proneural fundamental para el desarrollo de las células ciliadas de la cóclea ${ }^{28,29}$. Inmediatamente después de las mitosis terminales se expresa en todo el espesor del epitelio coclear en formación, para luego mantenerse sólo en las células ciliadas y no en las de sostén ${ }^{33}$. Además de otras alteraciones en el sistema nervioso central, los ratones homocigotos para la pérdida de Atoh1 no tienen células ciliadas en el oído interno ${ }^{28,29}$. El fenotipo normal se puede recuperar en ratones $\mathrm{KO}$ al reemplazar Atoh1 por atonal de mosca ${ }^{27}$. A la inversa, las moscas mutantes de atonal pueden recuperar el fenotipo al introducir
Atoh1 de ratón ${ }^{30}$. Atoh1 disminuye su expresión en mamíferos adultos, su función en este estadio no ha sido caracterizada ${ }^{23,31}$. Al sobreexpresar Atoh1 en roedores adultos y durante su desarrollo, tanto in vitro como in vivo se producen células ciliadas ectópicas ${ }^{8,23,31,32}$. Cuando la sobreexpresión se realizó en el órgano de Kölliker (grupo de células mediales al órgano de Corti y responsables de la producción de la membrana tectoria) las células generadas fueron capaces de atraer dendritas desde el ganglio espiral (nervio auditivo) $^{31}$ y de inducir a su alrededor la diferenciación hacia células de sostén (simulando neuromastos de línea lateral de peces) ${ }^{33}$. Probablemente esta última acción se produjo al estimularse la vía de Notch. El aumento de la expresión de Atoh1, cambia el destino celular hacia una célula ciliada y aumenta la expresión de Jag2, que interactúa con Notch1 en una célula contigua lo que hace que en esta última se aumente la expresión de Hes1 y 5 que inhiben la expresión de Atoh1 lo que modifica el 


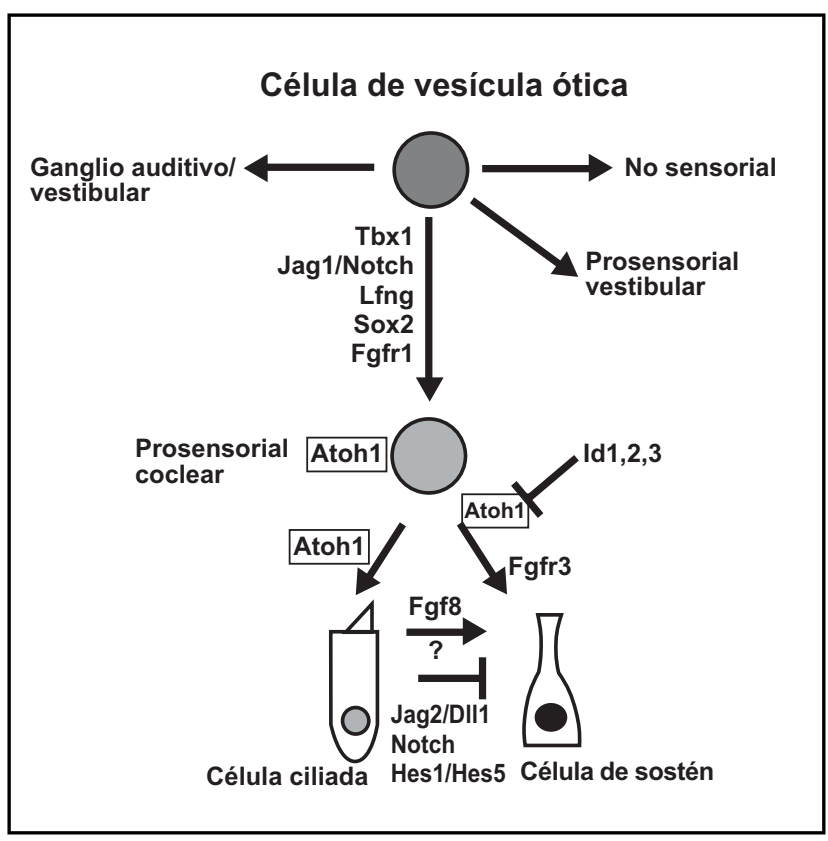

Figura 3. Determinación del destino celular en el órgano de Corti y función Atoh1: Las células de la vesícula ótica se pueden diferenciar en una de 4 tipos celulares: células prosensoriales cocleares, células prosensoriales vestibulares, neuronas del ganglio auditivo o vestibular y epitelio no sensorial. Las que se diferenciarán en células prosensoriales, en un comienzo expresan distintos genes (Tbx1, Jag1, Lfng, Fgfr1 y Sox2). Posteriormente todas ellas expresan Atoh1 el cual determina que su destino sea hacia célula ciliada. Al mismo tiempo, las células prosensoriales expresan Ids 1, 2, 3 que actúan inhibiendo la actividad de Atoh1. Las células que se diferenciarán en células ciliadas disminuyen la expresión de Id y aumentan la expresión de Atoh1 y la de los ligandos de Notch (Jag2 y DII1). La expresión de estos ligandos activan de Notch1 y de los genes HES 1 y HES5 en las células vecinas. La presencia de los genes HES y de Ids, disminuyen la expresión de Atoh1. Al mismo tiempo, las células ciliadas producen señales inductoras, incluyendo la activación de la vía Fgf, que induce a que las células vecinas se diferencien en células de sostén. Mientras se sabe que Fgf lleva al desarrollo de algunas células pilares, hay señales inductoras que aún están en estudio.

destino celular hacia una célula de sostén ${ }^{8}$. Esta vía interviene durante el desarrollo induciendo inhibición lateral, permitiendo que exista normalmente una fila de células ciliadas internas y tres filas de células ciliadas externas ${ }^{10}$ (Figura 3). Finalmente en cobayos adultos sordos se demostró mediante virus inyectados en la escala media que la sobrexpresión transitoria de Atoh1 en las células de sostén (cócleas carentes de células ciliadas) produce regeneración de células ciliadas y disminución de sus umbrales auditivos luego de dos meses ${ }^{32}$.

Aún no se ha desarrollado un tratamiento definitivo para la hipoacusia sensorioneural, y se busca la forma de regenerar células ciliadas. Las principales líneas de investigación en desarrollo comprenden el uso de terapia génica (supresión 0 activación de genes), introducción de células madres a la cóclea, y uso fármacos y factores de crecimiento ${ }^{34}$ (Figuras 4, 5 y 6). El estudio de la expresión génica en el órgano de Corti tanto durante su desarrollo como durante la etapa adulta ayudará a comprender mejor su fisiología y a desarrollar terapias en el futuro orientadas a tratar pacientes sordos.

* Parte del proyecto «Interferencia de la expresión de genes en el oído interno como herramienta molecular para regenerar células ciliadas» financiado por el concurso anual 2006 de la Sociedad Chilena de Otorrinolaringología, Medicina, Cirugía de Cabeza y Cuello, beca CONICYT doctorado y AT-24071080.

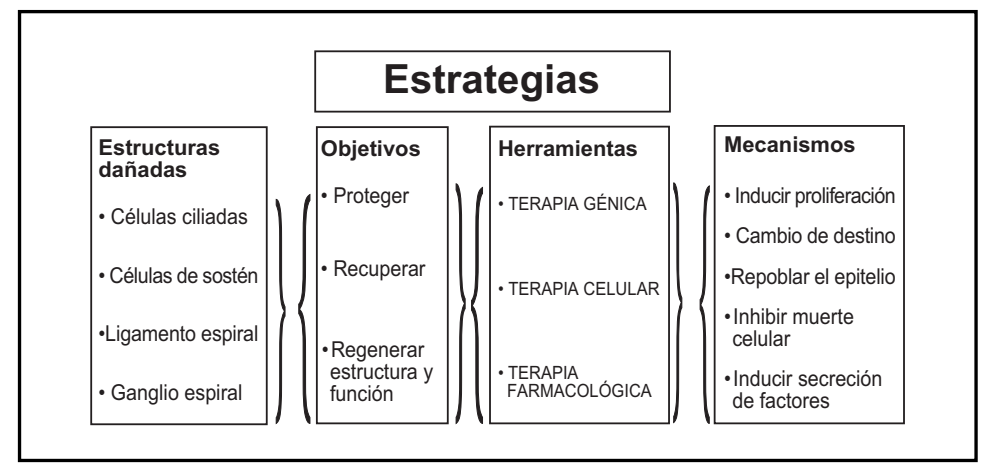

Figura 4. Esquema que muestra las distintas líneas de investigación o estrategias a emplear ante daño coclear. 


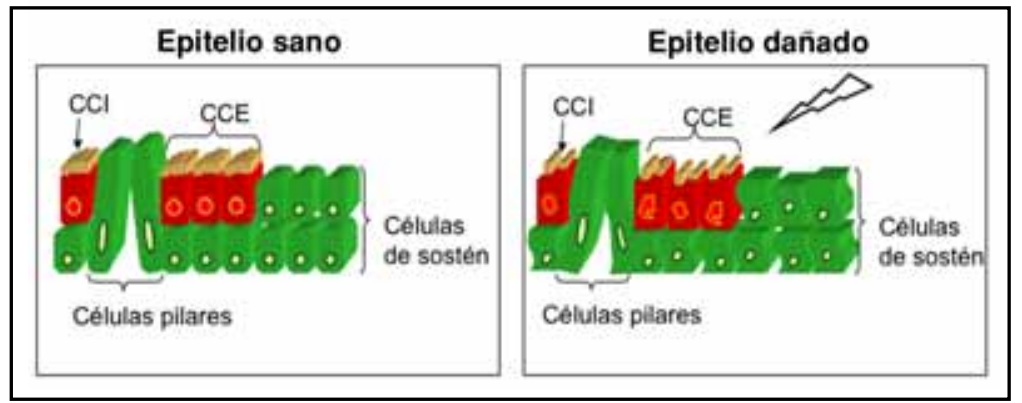

Figura 5. Esquema de órgano de Corti. A izquierda un epitelio normal y a derecha un epitelio dañado. CCI: célula ciliada interna; CCE: células ciliadas externas.

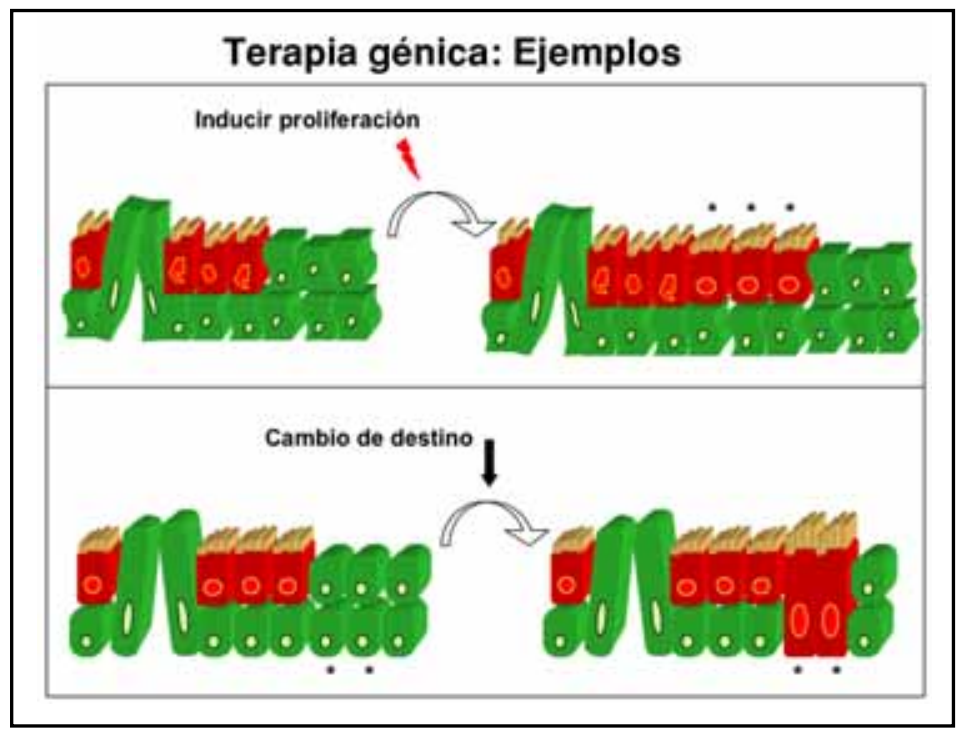

Figura 6. Esquemas que representan ejemplos de terapia génica. Arriba: Inducción de proliferación en un epitelio dañado donde se observa proliferación de células ciliadas (ver asteriscos). Abajo: Se representa el cambio de destino celular de células de sostén a células ciliadas (ver asterisco).

\section{BIBLIOGRAFÍA}

1. American Academy of pediatrics. Newborn and infant hearing loss: detection and intervention. Task Force on Newborn and Infant Hearing, 1998-1999. Pediatrics 1999; 103(2): 527-30.

2. Cruickshanks KJ, Wiley TL, Twees tS et al. Prevalence of hearing loss in older adults in Beaver Dam, Wisconsin: The epidemiology of hearing loss study. Am J Epidemiol 1998; 148: 879-86.

3. Schuknecht HF. Pathology of the ear. Segunda ed. Pennsylvania: Lea \& Febiger 1993.

4. HAWKINS JR JE. Comparative otopathology: aging, noise, and ototoxic drugs. Adv Otorhinolaryngol 1973; 20: 125-41.
5. Liberman MC, Gao J, He DZ, Wu X, Jia S, Zuo J. Prestin is required for electromotility of the outer hair cell and for the cochlear amplifier. Nature 2002; 419(6904): 300-4.

6. ERnSTRom G, Chalfie M. Genetics of sensory mechanotransduction. Annu Rev Genet 2002; 36: 411-53.

7. RUBEN RJ. Development of the inner ear of the Mouse: A radioautographic study of terminal mitosis. Acta Otolaryngol Supp/ 1967; 220: 1-43.

8. KeLLEY MW. Regulation of cell fate in the sensory epithelia of the inner ear. Nat Rev Neurosci 2006; 7(11): 837-49.

9. FekETe $D$, Wu DK. Revisiting cell fate specification in the inner ear. Curr Opin Neurobiol 2002; 12(1): 35-42. 
10. Hawkins RD, Lovett M. The developmental genetics of auditory hair cells (Review Issue). Hum Mol Genet 2004; 13(2): 289-96.

11. Harris JA, Cheng AG, Cunningham LL, MacDonald G, Raible DW, Rubel EW. Neomycin-induced hair cell death and rapid regeneration in the lateral line of zebrafish (Danio rerio). J Assoc Res Otolaryngol 2003; 4(2): 219-34.

12. COTANCHE, D.A. Regeneration of hair cell sterociliary bundles in the chick cochlea following severe acoustic trauma. Hear Res 1987; 30: 181-94.

13. Corwin JT, Cotanche DA. Regeneration of sensory hair cells after acoustic trauma. Science 1988; 240: 1772-4.

14. Ryals BM, RubeL EW. Hair cell regeneration after acoustic trauma in adult coturnix quail. Science 1988; 240: 1774-6.

15. Forge A, LI L, CorWin JT, NeviLl G. Ultrastructural evidence for hair cell regeneration in the mammalian inner ear. Science 1993; 259: 1616-19.

16. YamASOBA T., Kondo Y. Supporting cell proliferation after hair cell injury in mature guinea pig cochlea in vivo. Cell Tissue Res 2006; 325(1): 23-31.

17. Baek JH, Hatakeyama J, Sakamoto $\mathrm{S}$, Ohtsuka T, Kageyama R. Persistent and high levels of Hes1 expression regulate boundary formation in the developing central nervous system. Development 2006; 133(13): 2467-76.

18. Ross DA, RaO PK, Kadesch T. Dual roles for the Notch target gene Hes-1 in the differentiation of 3T3-L1 preadipocytes. Mol Cell Biol 2004; 24(8): 3505-13.

19. PIscione TD, Wu MY, QuAggin SE. Expression of Hairy/Enhancer of Split genes, Hes1 and Hes5, during murine nephron morphogenesis. Gene Expr Patterns 2004; 4(6): 707-11.

20. Cau e, Gradwohl G, Casarosa S, Kageyama R, Guillemot $F$. Hes genes regulate sequential stages of neurogenesis in the olfactory epithelium. Development 2000; 127(11): 2323-32.

21. Sage C, Huang M, Karimi K et al. Proliferation of functional hair cells in vivo in the absence of the retinoblastoma protein. Science 2005; 307(5712): 1114-8.

22. White PM, Doetzlhofer A, Lee YS, Groves AK, SEGIL N. Mammalian cochlear supporting cells can divide and trans-differentiate into hair cells. Nature 2006; 441(7096): 984-7.

23. ZHENG JL, GAO WQ Overexpression of Math1 induces robust production of extra hair cells in postnatal rat inner ears. Nat Neurosci 2000; 3: 580-6.

24. LoWenheim H, Furness DN, KIL J et al. Gene disruption of p27Kip1 allows cell proliferation in the postnatal and adult organ of Corti. Proc Natl Acad Sci USA 1999; 96: 4084-8.

25. BoekHoff-FalK G. Hearing in Drosophila: Development of Johnston's Organ and Emerging Parallels to Vertebrate Ear Development. Dev Dyn 2005; 232: $550-8$.

26. Jarman AP. Studies of mechanosensation using the fly. Hum Mol Genet 2002; 11(10): 1215-18.

27. Wang VY. Drosophila atonal Fully Rescues the Phenotype of Math1 Null Mice: New Functions Evolve in New Cellular Contexts. Curr Biol 2002; 12: 1611-16.

28. Bermingham NA, Hassan BA, Price SD et al. Math1: an essential gene for the generation of inner ear hair cells. Science 1999; 284: 1837-41.

29. Chen P, Johnson JE, Zoghbi HY, Segil N. The role of Math1 in inner ear development: Uncoupling the establishment of the sensory primordium from hair cell fate determination. Development 2002; 129: 2495-505.

30. Ben-Arie N, Hassan BA, Bermingham NA et al. Functional conservation of atonal and Math1 in the CNS and PNS. Development 2002; 127(5): 1039-48.

31. Kawamoto K, Ishimoto S, Minoda R, Brough DE, Raphael Y. Math1 Gene Transfer Generates New Cochlear Hair Cells in Mature Guinea Pigs In Vivo. J Neurosci 2003; 23(11): 4395-400.

32. IzUmikawa, M, Minoda R, Kawamoto K et al. Auditory hair cell replacement and hearing improvement by Atoh1 gene therapy in deaf mammals. Nat Med 2005; 11: 271-6.

33. Woods C, Montcouquiol M, Kelley MW. Math1 regulates development of the sensory epithelium in the mammalian cochlea. Nat Neurosci 2004; 7(12): 1310-8.

34. KROS CJ. How to build an inner hair cell: Challenges for regeneration. Hear Res 2007; 227(1-2): 3-10.

\footnotetext{
Dirección: Dr. Juan Cristóbal Maass 0.

Santos Dumont 999, Independencia. Santiago, Chile. E mail: jcmaass@yahoo.com
} 